\title{
EFEITO DA ADIÇÃO DE MICROLIGAS NA LAMINAÇÃO DE BOBINAS A QUENTE*
}

\author{
Felipe Farage David ${ }^{1}$ \\ Alisson Paulo de Oliveira ${ }^{2}$ \\ Ricardo José Faria ${ }^{3}$ \\ Romeu Thomaz Viana Junior ${ }^{4}$ \\ Edson Hugo Rossi 5 \\ Carlos Alberto Soares ${ }^{6}$ \\ José Herbert Dolabela da Silveira ${ }^{7}$
}

\section{Resumo}

A laminação de tiras a quente de bobinas de aço apresenta alta relevância devido a possibilidade de obtenção de diversos produtos para diferentes aplicações, tais como: construção civil, industria automotiva e implementos agrícolas. O controle das variáveis de processo, tais como temperatura de reaquecimento de placa, velocidade de resfriamento e temperatura de bobinamento, é determinante para obtenção da microestrutura e, por conseguinte, das propriedades mecânicas do material. O propósito desse trabalho é estudar o comportamento da microestrutura e das propriedades mecânicas com a variação da composição química (adição de microligas de nióbio e titânio), mantendo uma rota de laminação termomecânica similar na laminação de bobinas a quente. Os aços aplicados neste estudo foram o aço microligado ao nióbio e titânio equivalente ao ASTM A1018 HSLAS 50 Classe 1 e o aço carbono comum equivalente ao ASTM A1018 SS36 Tipo 2. Apesar do aço carbono comum apresentar carbono equivalente superior ao aço microligado, foi verificado maior limite de escoamento $\left(\sigma_{e}\right)$ no aço microligado ao nióbio e titânio. Dessa forma, aplicando tratamento termomecânico adequado no aço microligado é possível conseguir propriedades mecânicas melhoradas principalmente devido ao refino de grão e ao endurecimento da ferrita.

Palavras-chave: Laminação a quente; Tratamento termomecânico; Aço microligado; Steckel.

\section{Abstract}

\section{EFFECT OF ADDING MICROALLOYS IN HOT-ROLLED COILS}

The Hot-Rolled Coils from have a high relevance due to the possibility of obtaining various products for different applications, such as: structural steels, automotive industry and agricultural implements. The control of process variables, such as reheating temperature of the plate, cooling rate and coiling temperature is essential to obtain the microstructures and therefore the mechanical properties of the material. The purpose of this work is to study the behavior of the microstructure and mechanical properties by varying the chemical composition (adding the microalloys of Niobium and Titanium) and the similar thermomechanical rolling route in HotRolled Coils. The steels used in this study were the Niobium and Titanium microalloyed steels equivalent to ASTM A1018 HSLAS 50 Class 1 and carbon steel equivalent to ASTM A1018 SS36 Type 2. Despite the carbon steel has a high amount of carbon them the microalloyed steel, we observed higher Yield Strength in the microalloyed steel with Niobium and Titanium. Thus, applying the appropriate thermomechanical treatment in the microalloyed steel, is possible to improve the mechanical properties mainly due to grain refining and hardening of ferrite.

Keywords: Hot-Rolled Coils; Thermomechanical treatment; Microalloyed Steel; Steckel.

1 Engenheiro Metalurgista pelo IFES, Mestre em Engenharia Mecânica pela UFPE, Pesquisador do setor Pesquisa e Desenvolvimento de aços planos da Gerdau S.A, Ouro Branco, Minas Gerais, Brasil.

2 Engenheiro Metalurgista pela UFMG, Mestre em Engenharia Metalúrgica pela UFMG, Pesquisador do setor Pesquisa e Desenvolvimento de aços planos da Gerdau S.A, Ouro Branco, Minas Gerais, Brasil.

3 Engenheiro Metalurgista pela UFOP, Mestre em Engenharia Metalúrgica pela UFMG, Pesquisador do setor Pesquisa e Desenvolvimento de aços planos da Gerdau S.A, Ouro Branco, Minas Gerais, Brasil.

4 Engenheiro Metalurgista pela UFOP, Pesquisador do setor Pesquisa e Desenvolvimento de aços planos da Gerdau S.A, Ouro Branco, Minas Gerais, Brasil.

5 Engenheiro Metalurgista pela UFOP, Mestre em Engenharia Metalúrgica pela UFMG, Pesquisador do setor Pesquisa e Desenvolvimento de aços planos da Gerdau S.A, Ouro Branco, Minas Gerais, Brasil.

6 Engenheiro Metalurgista pela UFSJ, Pesquisador do setor Pesquisa e Desenvolvimento de aços planos da Gerdau S.A, Ouro Branco, Minas Gerais, Brasil.

7 Engenheiro Metalurgista pela UFMG, M.Sc. COPPE/UFRJ, Gerente da Laminação de Chapas Grossas da Gerdau S.A, Ouro Branco, Minas Gerais, Brasil. 


\section{INTRODUÇÃO}

Os aços microligados tem sido cada vez mais utilizados devido a combinação entre resistência mecânica, tenacidade e boa soldabilidade [1]. A aplicação de microligas como nióbio e titânio aumenta as propriedades mecânicas e possibilita melhor desempenho em produtos que exigem boa soldabilidade (por exemplo, aço para aplicação naval). A boa soldabilidade está atrelada principalmente à redução da quantidade de carbono na composição química do aço. Alternativamente, a elevada resistência é conseguida através de uma combinação de adição de microligas e de uma adequada rota de tratamento termomecânico seguido geralmente por resfriamento acelerado [2].

A adição de nióbio em aços microligados está relacionado ao efeito da precipitação dos carbonitretos de nióbio no contorno de grão da austenita [3]. Os cálculos de solubilidade mostram que o nióbio irá precipitar como $\mathrm{NbC}$ e $\mathrm{NbN}$ a temperaturas usuais de laminação, geralmente entre 800 e $1000^{\circ} \mathrm{C}$, que está dentro do regime de temperatura de deformação total para laminação a quente. $O$ nióbio, tanto em solução sólida como finamente precipitado em $\mathrm{Nb}(\mathrm{C}, \mathrm{N})$, contribuem para o aumento da propriedade mecânica do aço [4]. Os precipitados de baixa temperatura são muito finos (menores que $3 \mathrm{~nm}$ ), contribuindo mais efetivamente para o aumento do limite de escoamento [5]. Já o nióbio em solução sólida é eficaz em retardar a recristalização estática durante a laminação [4]. Já o titânio forma o precipitado TiN, sendo uns dos nitretos mais estáveis, formado durante a solidificação do aço, permanecendo estável durante a operação de reaquecimento da placa, evitando o crescimento do grão.

Neste trabalho, foi estudado o comportamento das propriedades mecânicas do aço microligado ao nióbio e titânio e aço carbono com tratamento termomecânico similar. A variação das propriedades mecânicas, especialmente o aumento no limite de escoamento e microdureza foi mensurado via, respectivamente, ensaio de tração e microdureza Vickers. Dessa forma, foi possível avaliar o efeito da adição dos microligantes sobre o refino de grão e o aumento da resistência do grão da ferrita, aumentando assim o limite de escoamento do material.

\section{MATERIAIS E MÉTODOS}

Duas classes de aços, um equivalente ao ASTM A1018 SS36 Tipo 2 e outro microligado ao nióbio e titânio equivalente ao ASTM A1018 HSLAS Grau 50 Classe 1 , foram escolhidas para estudar as propriedades das bobinas a quente em função da composição química e do tratamento termomecânico na laminação a quente. $O$ fluxograma do procedimento experimental está de acordo com a Figura 1. 


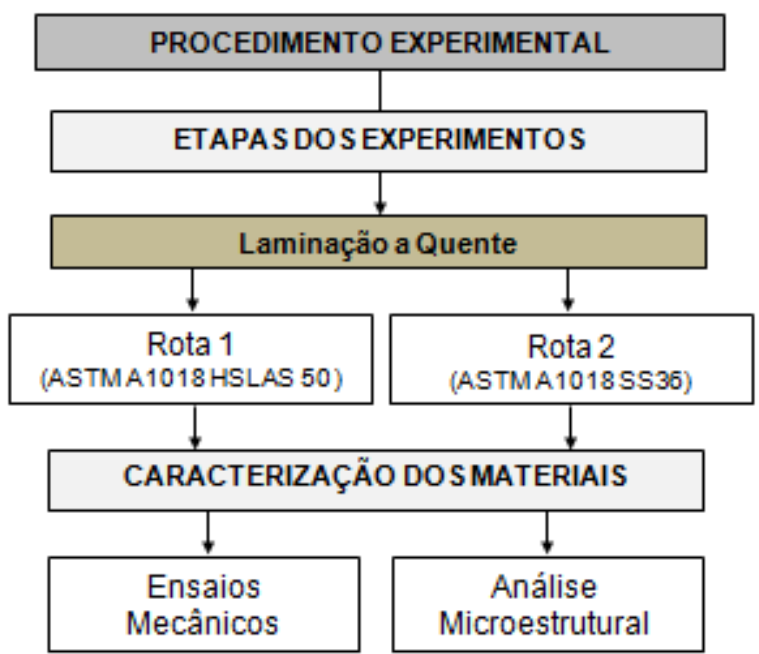

Figura 1. Fluxograma do procedimento experimental.

A faixa da composição química dos aços está de acordo com a Tabela 1.

Tabela 1. Faixa da composição química do aço aço microligado e do carbono comum

\begin{tabular}{cccccccc}
\hline $\begin{array}{c}\text { Aço } \\
\text { ASTM A1018 }\end{array}$ & $\mathbf{C}$ & Mn & Si & Nb & Ti & N (ppm) & $\begin{array}{c}\text { C equivalente, } \\
\text { máximo }\end{array}$ \\
\hline SS36T2 & $<0,25$ & $<1,35$ & $\ldots$ & $<0,008$ & $<0,025$ & $<0,014$ & $<0,40$ \\
\cline { 2 - 9 } HSLAS 50CL1 & $<0,23$ & $<1,50$ & $\ldots$ & $>0,005$ & $>0,005$ & $\ldots$ & $<0,30$ \\
\hline
\end{tabular}

A laminação a quente do aço microligado e do aço carbono foi realizado no laminador tiras a quente com resfriamento via laminar cooling. As rotas de produção estão descritas em detalhes na Tabela 2.

Tabela 2. Rotas termomecânicas utilizadas no laminador Stelmor

\begin{tabular}{cl}
\hline Rota & \multicolumn{1}{c}{ Descrição } \\
\hline 1 & $\begin{array}{l}\text { Aquecimento da placa do aço microligado acima de } 1200^{\circ} \mathrm{C} \text {, laminação na temperatura } \\
\text { de austenitização, seguido de resfriamento no laminar cooling objetivando uma } \\
\text { temperatura de bobinamento de } 600 \text { a } 620^{\circ} \mathrm{C} \text {. }\end{array}$ \\
\hline 2 & $\begin{array}{l}\text { Aquecimento da placa do aço carbono comum acima de } 1150^{\circ} \mathrm{C} \text {, laminação na } \\
\text { temperatura de austenitização, seguido de resfriamento no laminar cooling objetivando } \\
\text { uma temperatura de bobinamento de } 600 \text { a } 620^{\circ} \mathrm{C} .\end{array}$ \\
\hline
\end{tabular}

Como mostra a Tabela 2, o tratamento térmico no laminar cooling foi equivalente nos dois aços testados. A diferênça básica foi a temperatura final de reaquecimento da placa. No aço microligado, objetivou-se temperatura superior a $1200^{\circ} \mathrm{C}$ para garantir a solubilização do nióbio. Segundo a equação de Siciliano [6], a temperatura de solubilização do nióbio é de $1172^{\circ} \mathrm{C}$ para composição química do aço microligado mostrada na Tabela 1. As bobinas foram devidamente identificados e caracterizados em relação à metalografia e as propriedades mecânicas.

Os corpos de prova utilizados foram preparados e ensaiados de acordo com a norma ASTM A370 (Standard Test Methods and Definitions for Mechanical Testing of Steel Products) [7]. Para análise de microdureza foi utilizado o microdurômetro Shmadzu HMV-2 e o ensaio foi realizado com uma carga $10 \mathrm{~g}$. A impressão foi realizada exclusivamente na região ferrítica. Para análise metalográfica, foi utilizado o microscópio Leica DMLM com uso de luz polarizada. 


\section{RESULTADOS E DISCUSSÃO}

As microestruturas produzidas para cada aço (ASTM A1018 HSLAS 50 classe 1, ASTM A1018 SS36 tipo 2), foram analisadas via microscopia óptica, sendo utilizado um aumento de 500 vezes. A metalografia da seção transversal (perpendicular ao sentido da laminação a quente) é exposta na Figura 2. Todas as metalografias apresentaram predominância da fase ferrita pró-eutetóide poligonal (grãos brancos) em relação ao microcostituinte perlita (grãos acinzentados).

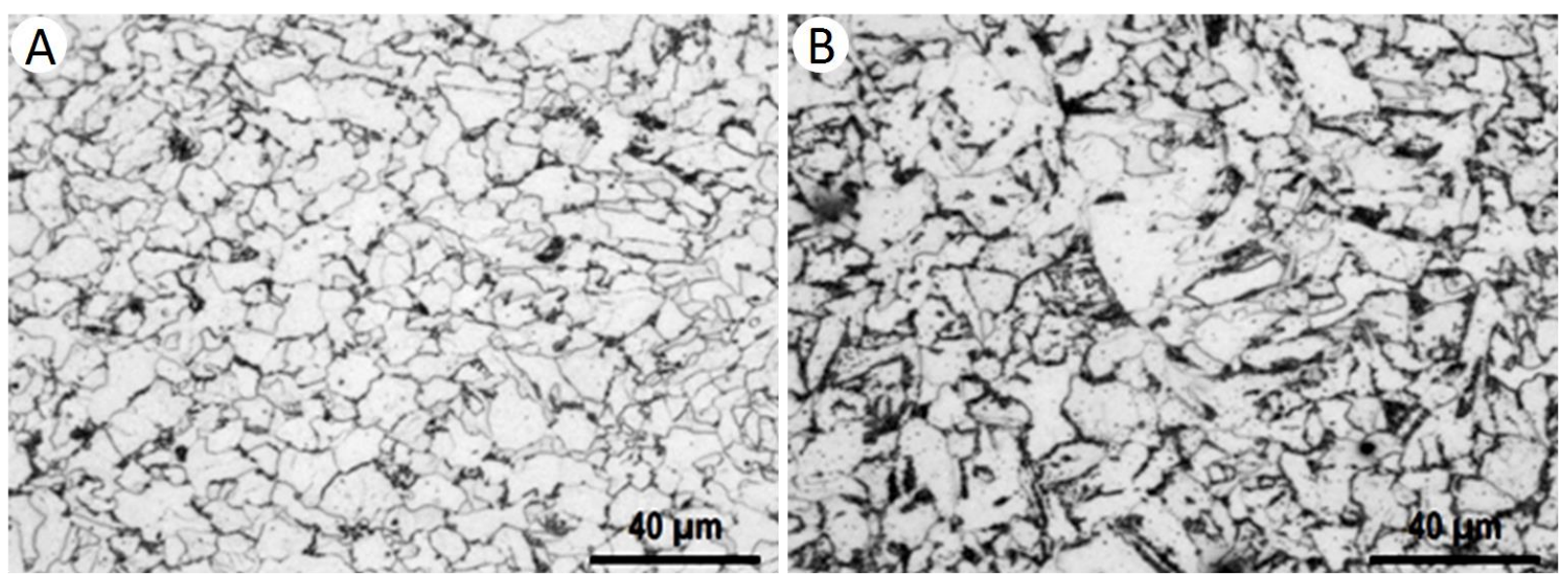

Figura 2. Microestrutura do aço (a) microligado e (b) aço carbono comum.

A Tabela 3 mostra a porcentagem dos microconstituintes presentes nos aços. De acordo com Yalamanchili et al. [8], a quantidade de ferrita pró-eutetóide é reduzida quanto maior for o teor de carbono e manganês. Logo, a bobina de aço ASTM 1018 SS36 possui o menor potencial para formação da ferrita pró-eutetóide. Estas tendências são confirmadas na quantificação dos microcostituintes, como mostra a Tabela 3.

Tabela 3. Porcentagem dos microconstituintes e tamanho de grão médio

\begin{tabular}{cccc}
\hline Aço & Ferrita (\%) & Perlita (\%) & Tamanho de Grão $(\mu \mathrm{m})$ \\
\hline $\mathrm{Nb} \mathrm{Ti}$ & 91 & 9 & 5,6 \\
\hline $\mathrm{C} \mathrm{Mn}$ & 82 & 18 & 6,6 \\
\hline
\end{tabular}

O aço microligado, após a laminação a quente, possui tamanho de grão inferior ao aço carbono comum SS36 (Tabela 3) apesar de ambos sofrerem o mesmo tratamento térmico no laminar cooling. Logo, há evidencias de precipitação de carbetos e nitretos de nióbio nos contornos de grão da austenita de maneira a promover um maior refino de grão. De acordo com Gunduz [9], a presença de partículas de segunda fase acarreta no bloqueio do crescimento do grão austenítico. Portanto, o menor tamanho de grão austenítico conduziu ao menor tamanho de grão ferrítico quando o material foi resfriado [10]. 


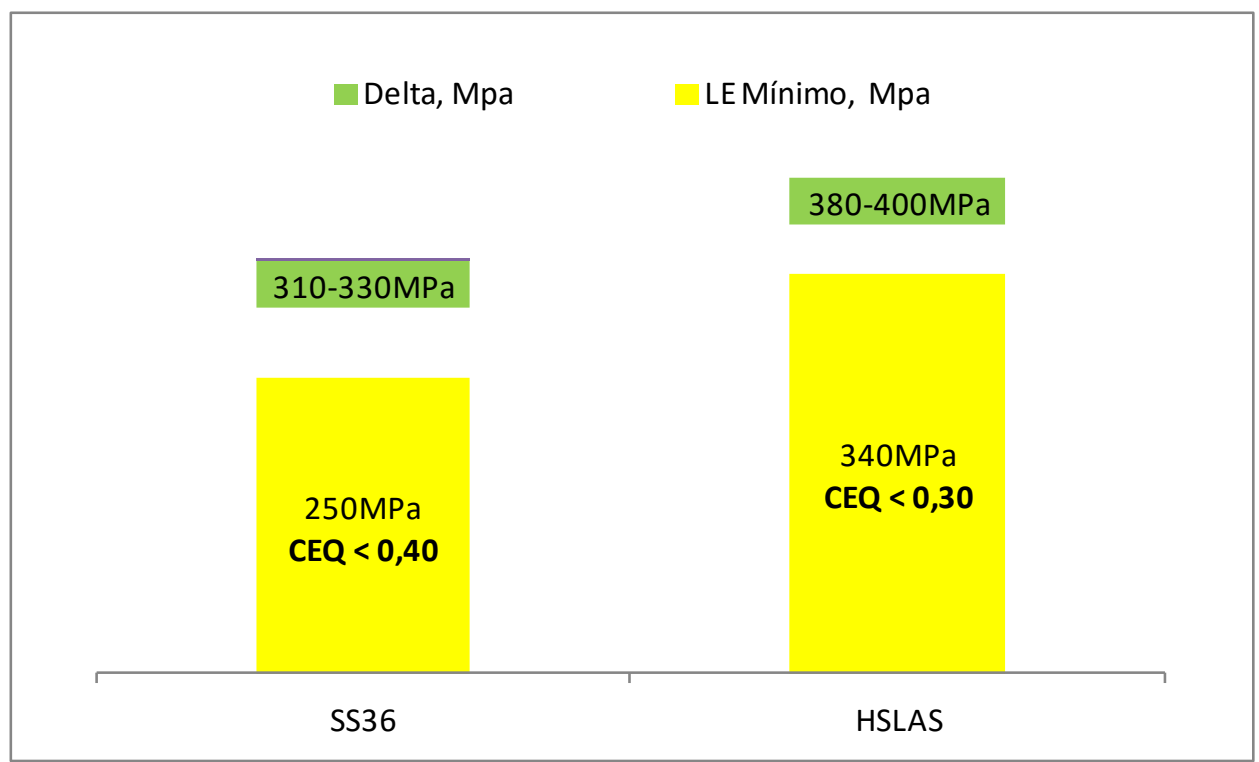

Figura 3. Relação entre o limite de escoamento e o carbono equivalente do aço microligado HSLAS e do aço carbono comum SS36. Faixa de valores de LE obtidos.

A relação entre o limite de escoamento $\left(\sigma_{e}\right)$ e o carbono equivalente está de acordo com a Figura 3. O aço microligado obteve o maior limite de escoamento após a laminação a quente, mesmo apresentando o menor carbono equivalente dos aços testados. Isso evidencia que 0 aço microligado apresentou 0 efeito do endurecimento via precipitados de segunda fase, sendo estes os carbetos e nitretos de nióbio. De acordo com Glodowisk [11], o $\mathrm{NbC}(\mathrm{N})$ precipita de maneira a restringir o crescimento dos grãos durante a austenitização e o grão mais fino conduz a um aumento no limite de escoamento na liga que contém nióbio. Deve-se considerar que a redução do tamanho de grão aumenta a área de contorno de grão por volume de material, que por sua vez, é uma eficiente barreira para movimentação das discordâncias. Ainda segundo Vervynckt et. al. [5], o nióbio precipita em finos carbonitretos na matriz (podendo estar abaixo de $3 \mathrm{~nm}$ ), sendo que estes precipitados também atuam como mecanismo de embarreiramento das discordâncias. Isso eleva o limite de escoamento do material. De fato o aço HSLAS possui o menor tamanho de grão (Tabela 3 ) e o maior $\sigma_{e}$ após o tratamento térmico no laminar cooling, mesmo exibindo menor carbono equivalente, inferior ao aço carbono comum.
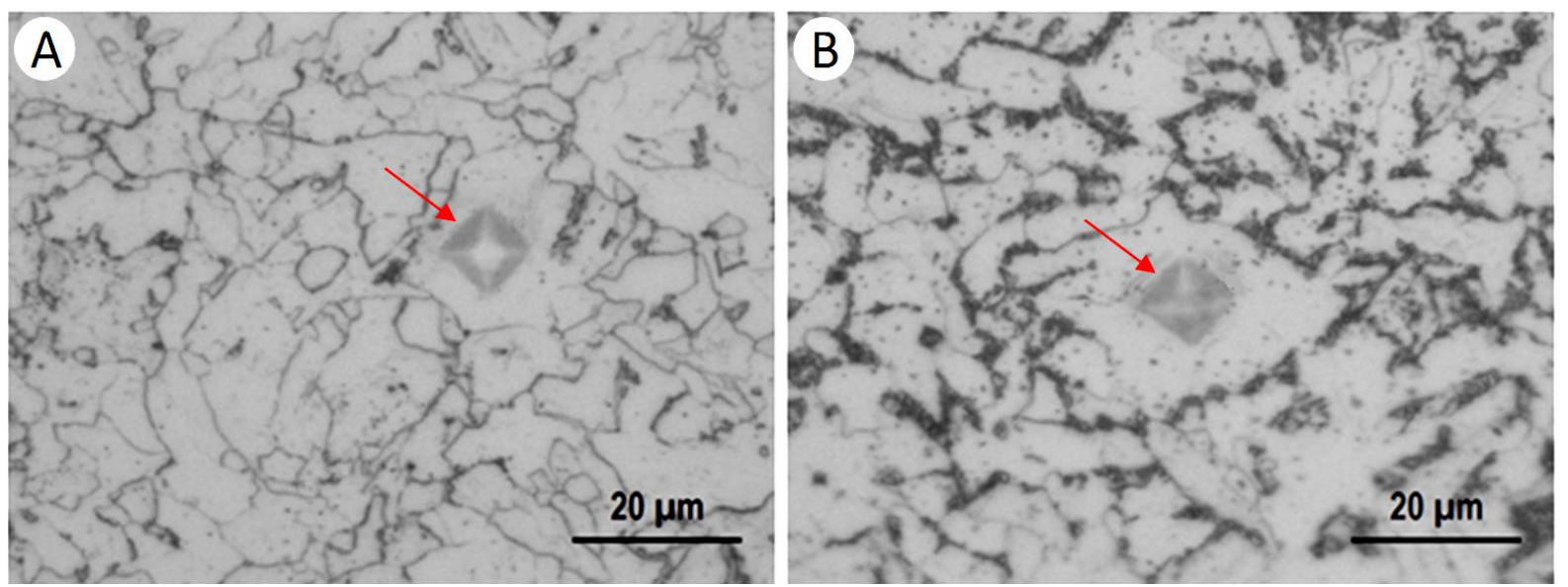

Figura 4. Impressão realizada pelo ensaio de microdureza Vickers no grão da ferrita do (a) aço microligado e (b) aço carbono comum. 
A Figura 4 exibe a impressão do ensaio de microdureza Vickers no grão da ferrita do aço microligado ASTM 1018 HSLAS 50-CL1 e do aço carbono ASTM 1018 SS36 T2. Foram realizados nas amostras dos aços estudados um total de 46 ensaios de microdureza. Os resultados estão apresentados na Figura 5.

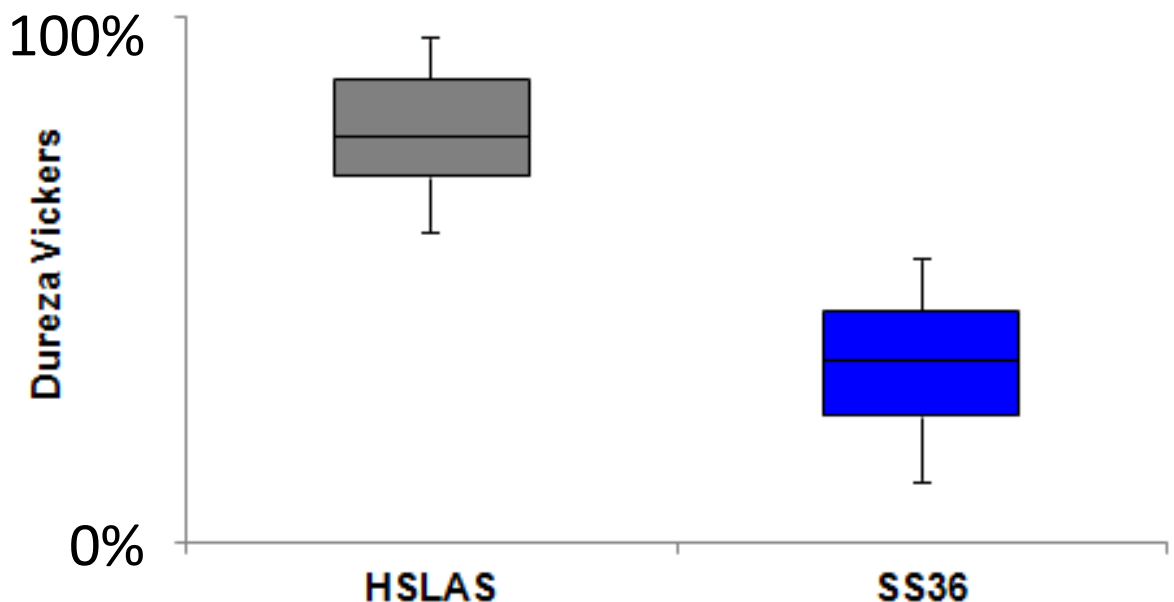

Figura 5. Dureza Vickers da ferrita no aço microligado HSLAS e do aço carbono SS36.

O aço microligado apresentou grãos ferríticos com maior dureza, sendo em média 21 Vickers superior ao aço carbono comum (Figura 5), mesmo exibindo menor teor de carbono e manganês (elementos endurecedores da ferrita). Segundo Campos et al. [12], a precipitação de finos carbonitretos de nióbio ocorrem durante a transformação da austenita para ferrita na laminação a quente de aços microligados, contribuindo significativamente para o aumento da resistência do grão ferrítico.

\section{CONCLUSÃo}

A bobina de aço microligado ASTM 1018 HSLAS Grau 50 CL1 apresentou em média maior limite de escoamento apesar de possuir o menor carbono equivalente em relação ao aço carbono comum ASTM 1018 SS36 T2. Este comportamento é justificado devido ao menor tamanho de grão exibido pelo aço microligado. Portanto, com a aplicação do tratamento termomecânico apropriado é possível promover endurecimento via precipitação de carbetos e nitretos de nióbio, de maneira a reduzir o tamanho de grão austenítico durante a laminação a quente.

Análise de microdureza Vickers nos grãos individuais da ferrita se mostrou hábil para revelar a influencia dos precipitados em aços microligados, aumentando siginificativamente a dureza desta fase microestrutural em relação ao aço carbono comum.

\section{Agradecimentos}

Os autores agradecem a Gerdau S.A pelo apoio ao projeto. 


\section{REFERÊNCIAS}

1 Fan L, Wang T, Fu Z, Zhang S, Wang Q. Effect of Heat-Tratment on-line temperature on the microstructure and tensile properties of a low carbon $\mathrm{Nb}$-microalloyed steel. Materials Science \& Engineering A. 2014;1(607): 559-568.

2 Anijdana SHM, Rezaeianb A, Yuea S. The effect of chemical composition and austenite conditioning on the transformation behavior of microalloyed steels. Materials Characterization. 2012;1(63): 27-38.

3 Jansto SG. Applied metallurgy of the microniobium alloy approach in long and plate products. Metal. 2012;5(23): 1-7.

4 Homsher CN. Determination of the non-recrystallization temperature (tnr) in multiple microalloyed steels. 2013. $106 \mathrm{f}$. Degree of Master of Science (Metallurgical and Materials Engineering ) - Colorado School of Mines, Colorado. 2013.

5 Vervynckt S, Verbekena K, Thibauxc P, Houbaert Y. Recrystallization-precipitation interaction during austenite hot deformation of a $\mathrm{Nb}$ microalloyed steel. Materials Science \& Engineering A. 2011;1(528): 5519-5528.

6 SICILIANO JR. Mathematical Modeling of the Hot Strip Rolling of $\mathrm{Nb}$ Microalloyed Steels. Ph.D. Thesis, McGill University, February 1999, 165 p.

7 AMERICAN SOCIETY FOR TESTING AND MATERIALS. A370: Standard Test Methods and Definitions for Mechanical Testing of Steel Products. West Conshohocken, 2014.50 p.

8 Yalamanchili B, Power PM, Lanham D. A Technical Review of Industrial Practices for Decreasing the Strain Hardening Rate of Low Carbon Steel Wire. Wire \& Cable Technical Symposium at wai's74th annual convention, Texas, Junho, 2004. 11p.

9 Gunduz S. Static strain ageing behaviour of dual phase steels. Materials Science and Engineering A. 2008:1(486): 63-71.

10 Jahazi $M$, Eghbali $B$. The influence of hot forging conditions on the microstructure and mechanical properties of two microalloyed steels. Materials Processing Technology. 2001:1(113): 594-598.

11 Glodowski RJ. A review of vanadium microalloying in hot rolled steel sheet products. International Seminar on Application Technologies of Vanadium in Flat - Rolled Steels, Suzhou, 2005. 9p.

12 Campos SS, Morales EV, Kestenbach J. Detection of interphase precipitation in microalloyed steels by microhardness measurements. Materials Characterization Materials. 2004:1(52): 379-384. 